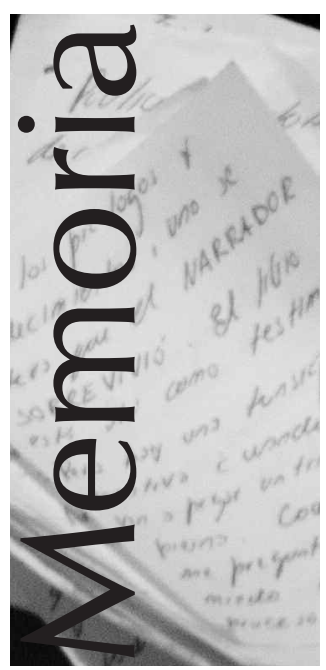

\title{
¿Quién es el Dr. Alvarado?
}

\author{
Who is Dr. Alvarado?
}

Jauretche, Arturo ${ }^{1}$

RESUMEN Este texto, escrito por Arturo Jauretche, recupera la figura del Dr. Carlos Alberto Alvarado (1904-1986) quien, en tiempos en que Ramón Carrillo era secretario de Salud Pública de la Nación, dirige una campaña que logra controlar el paludismo en el noroeste argentino con una reducción muy importante del número de casos, alcanzando una amplia repercusión mundial. En 1955, el Dr. Alvarado es separado de su cargo por la Revolución Libertadora, momento en que la Organización Panamericana de la Salud lo designa asesor regional y entre 1959 y 1964 lo nombran jefe del programa de erradicación de la malaria de la Organización Mundial de la Salud, en Ginebra, Suiza. A su regreso al país en 1966, organiza el Plan de Salud Rural, creando para ello la figura del "agente sanitario" y la "ronda sanitaria" anticipándose a conceptos que varios años después se plasmarían en la Atención Primaria de la Salud. El texto de Jauretche fue publicado originalmente en 1967 en el libro Los profetas del odio, por la editorial de Arturo Peña Lillo, editor de los grandes títulos del "pensamiento nacional" argentino. Su reedición en la sección "Memoria e historia" es un modo de rendir homenaje a una de las figuras indiscutibles de la Salud Pública argentina.

PALABRAS CLAVE Historia del Siglo XX; Paludismo; Argentina.

ABSTRACT This text, written by Arturo Jauretche, recovers the figure of Dr. Carlos Alberto Alvarado (1904-1986). When Ramón Carrillo was secretary of Public Health of the Nation, Dr. Alvarado led a campaign to control malaria in the Argentine northwest, achieving an important reduction in the number of cases and generating wide international repercussions. In 1955, Dr. Alvarado was resigned from his post by the Revolución Libertadora, at which time he was designated regional advisor by the Pan-American Health Organization, and later chief of the malaria eradication program of the World Health Organization in Geneva, Switzerland between 1959 and 1964. Upon his return to the country in 1966 he organized the Rural Health Plan and created the figure of the "public health agent" and "public health rounds," anticipating concepts that would later be developed within Primary Health Care. Jauretche's text was originally published in 1967 in the book Los profetas del odio, by the publishing house of Arturo Peña Lillo, editor of the great works of Argentine "national thought." This re-edition in the section "Memory and history" is a way of paying homage to one of the indisputable leaders of Public Health in Argentina.

KEY WORDS History, 20th Century; Marsh Fever; Argentina.

\footnotetext{
1 Pensador, escritor y político argentino (1901-1974).
} 
Si Ud. quiere conocerlo personalmente tendrá que viajar hasta Lozano, allá, camino a la Quebrada de Humahuaca, donde es propietario de un pequeño "motel" que le ofrecerá su hospitalidad. Es muy posible que la gran prensa Ilegue a hacerlo famoso como hotelero: ¡más difícil es que lo propicien para el Premio Nobel o para la Academia de Ciencias!

El Dr. Alvarado, estudioso investigador, pertenecía al antiguo Departamento Nacional de Higiene, donde estaba especializado en la lucha antipalúdica. En esa época todo el Noroeste Argentino padecía el paludismo como una endemia tan grave que todos los años había 120.000 enfermos nuevos. Los procedimientos que se aplicaban para combatir la enfermedad transmitida por el mosquito específico, eran los clásicos: limpieza de las riberas de los arroyos y canales, hacer circular las aguas para que no se estancasen, y a falta de mayores recursos preventivos la distribución de las dosis de quinina a los afectados y a las posibles víctimas. (Aún recuerdo cómo me zumbaban los oídos, por efecto de la quinina, cada vez que viajaba a la zona endémica: Santiago del Estero, La Rioja, Catamarca, Tucumán, Salta. La lucha del Departamento Nacional de Higiene no daba resultados porque además la enfermedad actuaba sobre nativos subalimentados en su infancia, situación que ahora parece retornar gracias a los que se empeñan en llevar al país a "niveles internacionales" de fluencia económica).

El Dr. Alvarado partió de una comprobación: en las zonas típicamente palúdicas, de pantanos y selvas y de húmedo clima tropical, como Chaco, Formosa, Corrientes, Misiones, solo aparecían brotes epidémicos que también desaparecían circunstancialmente, mientras que en el Noroeste la enfermedad era endémica, de acción continuada y localizada, justamente donde no había pantanos, ni tupida vegetación, sino que por el contrario, las aguas que se estancaban lo hacían sobre la arena y entre las piedras, en los derrames de los ríos cordilleranos y del Aconquija, a pleno sol y aire. Esto llevó al Dr. Alvarado a la convicción de que el mosquito transmisor era una especie distinta del tradicional. Investigando sobre esta base, durante largos años, llevó a comprobar que a diferencia de las larvas del mosquito clásico del paludismo, que prosperaban en un ambiente húmedo y sombrío, el mosquito vehículo de la enfermedad en la zona, necesitaba que su larva tuviera exposición solar y aguas limpias.

Este descubrimiento es técnicamente mucho más importante que el que se atribuyó el Dr. Houssay, producto de la casualidad y la comprobación ajena. Y lo es mucho más si se lo considera del punto de vista social y nacional.

Importaba además una revolución en la técnica de la lucha antipalúdica, y el Dr. Alvarado hubo de enfrentarse con todo el aparato burocrático y científico que, ya se sabe, es siempre rutinario y opuesto a las innovaciones.

Pero en ese entonces (1945) se puso en marcha una voluntad nacional. El Dr. Ramón Carrillo, desde el Ministerio de Salud Pública, encaró la medicina con criterio preventivo, y no el simplemente curativo que había predominado hasta entonces, y ante la resistencia y el horror de los expertos consagrados puso el hombro y empujó con toda su fuerza a la obra del Dr. Alvarado, dándole mano libre y recursos. Sobre la base de su descubrimiento y apelándose a una dedetización sistemática y a una acción masiva, el paludismo desapareció del Noroeste argentino en menos de dos años. ¡De 120.000 casos anuales, la estadística bajó a 120! ¡Al 1 por 1.000! Se realizó la más grande hazaña de la medicina argentina y tal vez de la mundial. Así lo debieron entender en el extranjero porque cuando el Dr. Alvarado, en premio de su gigantesca tarea fue separado de su cargo después de 1955, lo Ilamaron del exterior y durante muchos años fue en el correspondiente organismo de las Naciones Unidas el Director de la lucha antipalúdica mundial. 
Si lo echaron, menos habrían de proponerlo para un Premio Nobel o para una Academia. Minuciosamente la gran prensa oculta la realización de esta hazaña y el nombre de quien la hizo: Alvarado, y quien la empujó: Carrillo. Este último murió en extrema pobreza hace muchos años en Belén, Brasil, y allá están sus restos que el gobierno de entonces no permitió repatriar.

\section{FORMA DE CITAR}

Jauretche A. ¿Quién es el Dr. Alvarado? Salud Colectiva. 2012;8(1):81-83. 